\title{
ELEVATION IN RAT BRAIN HISTAMINE CONTENT AFTER FOCUSED MICROWAVE IRRADIATION $^{1}$
}

\author{
LINDSAY B. Hough ${ }^{2}$ and EdWard F. Domino \\ Department of Pharmacology, University of Michigan, Ann Arbor, MI 48109, U.S.A.
}

(Received 10 December 1976. Accepted 24 February 1977)

\begin{abstract}
Microwave irradiation focused on the head of small rodents is now widely used as a means of more accurately measuring acetylcholine, choline, cyclic AMP, and several other important brain constituents. Because of its probable neurotransmitter role and rapid turnover, a similar approach was taken to study brain histamine. Histamine was measured by a modified radio-enzymatic method and was found to be nearly tripled in brains from microwave treated rats, compared to decapitation controls (124 vs $42 \mathrm{ng} / \mathrm{g}$ ). Possible explanations include a microwave-induced inactivation of histamine breakdown, a microwave-induced redistribution of previously unmeasured histamine, and microwaveinduced histidine decarboxylation. Brain histamine remained unchanged up to $30 \mathrm{~min}$ after decapitation and microwave heated brains from decapitated rats also had elevated histamine levels, indicating that brain histamine levels in decapitated rats do not represent the remainder of a rapidly depleting pool. No evidence for previously unmeasured histamine was found. Furthermore, microwave irradiation did not enhance the formation of $\left[{ }^{3} \mathrm{H}\right]$ histamine after intraventricular $\left[{ }^{3} \mathrm{H}\right]$ histidine administration, indicating a lack of microwave-induced histidine decarboxylation. It is concluded that the elevation in rat brain histamine after focused microwave irradiation is probably not artifactual, although the mechanișm responsible for this phenomenon remains obscure.
\end{abstract}

THE APPLICATION of focused microwave irradiation to the head of experimental animals facilitates the accurate measurement of several important substances by rapidly inactivating brain protein. GuIDotri et al. (1974) demonstrated the importance of this method for determining cyclic nucleotide content. Furthermore, the use of microwave heating is necessary for accurately measuring acetylcholine and choline (GUIDOTTI et al., 1974; StavinoHA et al., 1973). More recently, several other putative neurotransmitter levels have been measured using this method (WEINTRAUB et al., 1975; RiCHARDSON \& SCUDDER, 1976).

A variety of evidence exists suggesting histaminergic transmission in many species (SCHWARTZ, 1975; TAYLOR, 1975). Since TAYLOR \& SNYDER (1971) reported that brain histamine was elevated after immersion of rats in liquid nitrogen and because a rapid turnover of brain histamine exists (Pollard et al., 1974; DisMUKES \& SNYDER, 1974), the effect of focused microwave irradiation on rat brain histamine was studied. Hypotheses regarding the effects observed have been postulated and tested as described in this paper.

\footnotetext{
${ }^{1}$ A preliminary form of this research was presented at the Fall Meetings of the American Society for Pharmacology and Experimental Therapeutics in August, 1975 (Hough \& Domino, 1975).

${ }^{2}$ Predoctoral Fellow of USPHS Training Grant 5-T01 GM-00198.
}

\section{MATERIALS AND METHODS}

Male albino rats (Holtzman) weighing $200-400 \mathrm{~g}$ were maintained in $12 \mathrm{~h}$ light-dark cycles and used for all studies. Animals were either decapitated at room temperature $\left(22-24^{\circ} \mathrm{C}\right)$ or subjected to microwave irradiation followed by decapitation $2-4 \mathrm{~h}$ into the light cycle. The microwave oven was a Litton model $70 / 50$ adapted so that $1.3 \mathrm{~kW}$ is focused and pulsed on the rat's head. Rats were secured in a suitable restrainer and were killed by 3-6s of microwave heating. This treatment routinely heats the brain to $70-80^{\circ} \mathrm{C}$. Brains were removed, weighed, and homogenized in $4 \mathrm{ml}$ of ice cold $0.05 \mathrm{M}$-sodium phosphate buffer, pH 7.9 containing $0.1 \%$ Triton X-100 in $30-45 \mathrm{~s}$ unless otherwise specified. Homogenates were placed in a boiling water bath for $10 \mathrm{~min}$, cooled in ice, and centrifuged for $20 \mathrm{~min}$ at $20,000 \mathrm{~g}$. Supernatants or pellets were measured by the radioenzymatic method of TAYLOR \& SNYDER (1971), as modified by BEAVEN et al. (1971). Samples or histamine standards (Sigma) were incubated with $\left[{ }^{14} \mathrm{CH}_{3}\right] \mathrm{S}$-adenosyl-L-methionine (New England Nuclear) and $\left[\mathrm{G}-{ }^{3} \mathrm{H}\right]$ histamine in the presence of a partially purified histamine methyltransferase (BEAVEN et al., 1971). In other studies, side chain $\left[{ }^{3} \mathrm{H}\right]$ histamine was synthesized according to the method of BEAVEN (1975) and used in place of $\left[\mathrm{G}-{ }^{3} \mathrm{H}\right]$ histamine. The reaction was terminated by the addition of $0.4 \mathrm{~N} \mathrm{HClO}_{4}$ containing $1 \mathrm{mg} / \mathrm{ml} \mathrm{1,4-meth-}$ yl-histamine hydrochloride (Calbiochem). The labeled methylhistamine was extracted into chloroform after treatment with $10 \mathrm{~N} \mathrm{NaOH}$. The chloroform fraction was washed with $3 \mathrm{~N} \mathrm{NaOH}$ and evaporated in a scintillation vial under nitrogen. Ten $\mathrm{ml}$ of toluene scintillation fluid (TAYLOR \& SNYDER, 1971) was added and the ${ }^{14} \mathrm{C}$ and ${ }^{3} \mathrm{H}$ counted in a Beckman LS-200. The ${ }^{14} \mathrm{C} /{ }^{3} \mathrm{H}$ ratio is linear with histamine concentration from $0.1-2.0 \mathrm{ng}$. Paper 
chromatographic analyses of the chloroform extracts were carried out using the solvent systems of TAYLOR \& SNYDER (1971). Histamine values were expressed as $\mathrm{ng}$ histamine (free base) per $\mathrm{g}$ brain wet weight and per $\mathrm{mg}$ brain protein. Protein was assayed per LowRy et al. (1951). Brain homogenates from decapitated rats were also placed in $10 \mathrm{ml}$ vials and microwave heated for $6 \mathrm{~s}$.

The pellets obtained from heated homogenates were assayed for histamine after they were resuspended in $3 \mathrm{ml}$ of the phosphate buffer. One $\mathrm{ml}$ of $10 \mathrm{~N} \mathrm{NaOH}$ was added and the mixture was mechanically extracted with $10 \mathrm{ml}$ of $n$-butanol-chloroform $(3: 2)$ for $30 \mathrm{~min}$. Following centrifugation $(1000 \mathrm{~g})$ the organic layer was removed, evaporated to dryness under nitrogen and resuspended in $2 \mathrm{ml}$ of the buffer. The solution was assayed directly or purified by diluting to $8 \mathrm{ml}$ with buffer followed by ion exchange chromatography using $4 \times 0.75 \mathrm{~cm}$ beds of Biorex 70 (200-400 mesh, Biorad) equilibrated in buffer. The columns were washed twice with $5 \mathrm{ml} \mathrm{H}_{2} \mathrm{O}$, followed by elution with $2 \mathrm{ml} 1 \mathrm{~N} \mathrm{HCl}$ and $2 \mathrm{ml} \mathrm{H}_{2} \mathrm{O}$. The eluates were combined, evaporated to dryness in vacuo, resuspended in buffer and assayed. Total recovery was determined both by the addition of histamine to aliquots of samples and with $\left[{ }^{3} \mathrm{H}\right]$ histamine. All results are corrected for recovery. In other experiments rat brain homogenates were purified by adding supernatants directly to the columns without prior extraction.

For intraventricular injections of $\left[{ }^{3} \mathrm{H}\right]$ histidine, chronic intraventricular cannulae were surgically implanted into the lateral ventricle by the method of DEBALBIAN-VERSTER et al. (1971). The $\mathrm{L}-\left[2,5-{ }^{3} \mathrm{H}\right]$ histidine $(60 \mathrm{mCi} / \mathrm{mmol})$ (Amersham-Searle) was purified prior to injection by chromatography on ITLC type SG paper (Gelman, Ann Arbor) with $n$-propanol-1 $\mathrm{N} \mathrm{NH}_{4} \mathrm{OH}$ (3:1). After air drying, the area corresponding to genuine histidine was cut out, eluted into $4 \mathrm{ml} \mathrm{H}_{2} \mathrm{O}$, filtered through a millipore filter. evaporated to dryness. and resuspended in $0.9 \%$ $\mathrm{NaCl}$ to a concentration of $1 \mu \mathrm{Cj} / \mu \mathrm{l}$. Rats received intraventricular injections of $20 \mu \mathrm{l}$ of this solution. Thirty min later, the animals were either decapitated or subjected to microwave treatment. Brains were removed, homogenized in $10 \mathrm{ml} 0.4 \mathrm{~N} \mathrm{HClO}_{4}$ and centrifuged $(20,000 \mathrm{~g} \times 10 \mathrm{~min})$. Aliquots $(0.1 \mathrm{ml})$ were added to $10 \mathrm{ml}$ Aquasol (New England Nuclear) and counted for total radioactivity. Five $\mathrm{ml}$ of $\mathrm{H}_{2} \mathrm{O}$ containing $10 \mathrm{mg}$ histidine, $1 \mathrm{mg}$ histamine, $1 \mathrm{mg}$ methylhistamine were added to $3 \mathrm{ml}$ of the supernatant fraction. The $\mathrm{pH}$ was adjusted to 8.0 with $1 \mathrm{~N} \mathrm{NaOH}$; an additional $1 \mathrm{ml}$ of $0.2 \mathrm{~N}$ Tris buffer (Sigma), pH 8.0, was added. This solution was added to the Biorex columns described above. These were washed twice with $10 \mathrm{ml}$ of $0.01 \mathrm{~N} \mathrm{HCl}$ and eluted with $2 \mathrm{ml}$ of $1 \mathrm{~N} \mathrm{HCl}$. Two $0.9 \mathrm{ml}$ aliquots of the eluate from each column were made basic with $0.3 \mathrm{ml} 10 \mathrm{~N} \mathrm{NaOH}$ and saturated with $\mathrm{NaCl}$. One aliquot was extracted with $5 \mathrm{ml}$ of $n$-butanol-chloroform (3:2) and the other with $5 \mathrm{ml}$ chloroform for $30 \mathrm{~min}$. Each organic fraction was washed with $5 \mathrm{ml} 2 \mathrm{~N} \mathrm{NaOH}$, evaporated under nitrogen and counted. Two million c.p.m. of pure $\left[{ }^{3} \mathbf{H}\right]$ histidine added to a brain homogenate and taken through this procedure yielded only 100 c.p.m. in the butanol-chloroform and 45 c.p.m. in the chloroform extracts. Recoveries of labeled histamine and methylhistamine (synthesized according to BEAVEN \& JACOBSON (1971) were $65 \%$ in the butanol-chloroform samples. The recovery in chloroform was $60 \%$ of methylhistamine but less than $3 \%$ of histamine. This method was developed by modification of the methods of Pollard et al. (1974) and

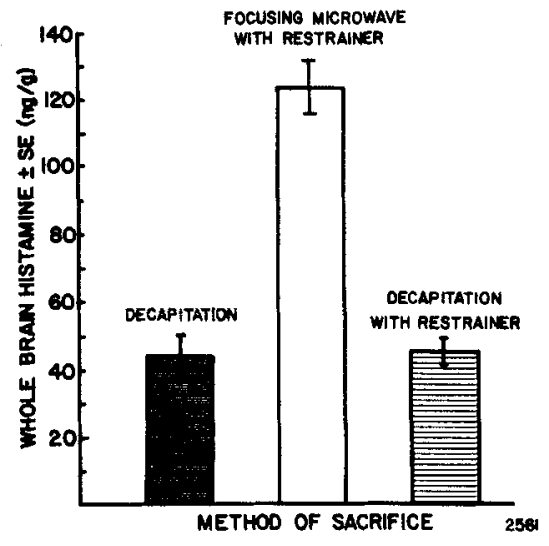

FIG. 1. Rat whole brain histamine after decapitation and focused microwave irradiation. In this and subsequent figures mean whole brain histamine \pm S.E. for groups of 8 animals are shown. Microwave irradiation was for 3-6 s. Note the marked elevation in brain histamine after the microwave treatment.

SNYDER et al. (1964). Results are corrected for recovery and are expressed as labeled histamine and methylhistamine formed in each brain divided by the total label found in each brain. The identity of the contents of the organic extracts was verified by paper chromatography as described above

\section{RESULTS}

The rat brain histamine content after microwave irradiation was nearly tripled compared to decapitation controls $(124 \pm 5$ vs $42 \pm 8 \mathrm{ng} / \mathrm{g}$, Fig. 1). Because of the stress associated with the restrainer, a necessary control was decapitation with the restrainer. Values obtained in this manner were identical to decapitation controls. Microwave irradiation applied to histamine standards was without effect.

Evidence that histamine was being specifically and accurately measured was obtained. Brain homogenates from microwave-treated rats were assayed and the resulting chloroform extracts were chromatographed. More than $95 \%$ of the total radioactivity co-chromatographed with methylhistamine in two different solvent systems. The recovery of unlabeled histamine added to such brain homogenates was always greater than $90 \%$. Results identical to those in Fig. 1 were also found when brains were homogenized in $0.4 \mathrm{~N} \mathrm{HClO}_{4}$ and subsequently purified by organic extraction. When supernatants from the brains of decapitated or microwave-treated rats were purified by ion exchange chromatography, the histamine values measured were identical to those obtained from the assay of unpurified samples (Fig. 2).

Three explanations seem possible for the microwave-decapitation discrepancy: (1) that microwave treatment arrests a rapid enzymatic process which metabolizes histamine under conditions of decapitation, (2) that microwave treatment liberates some 'bound' histamine not found in the supernatant after decapitation, or (3) that microwave treatment produces histamine from some other substance. 


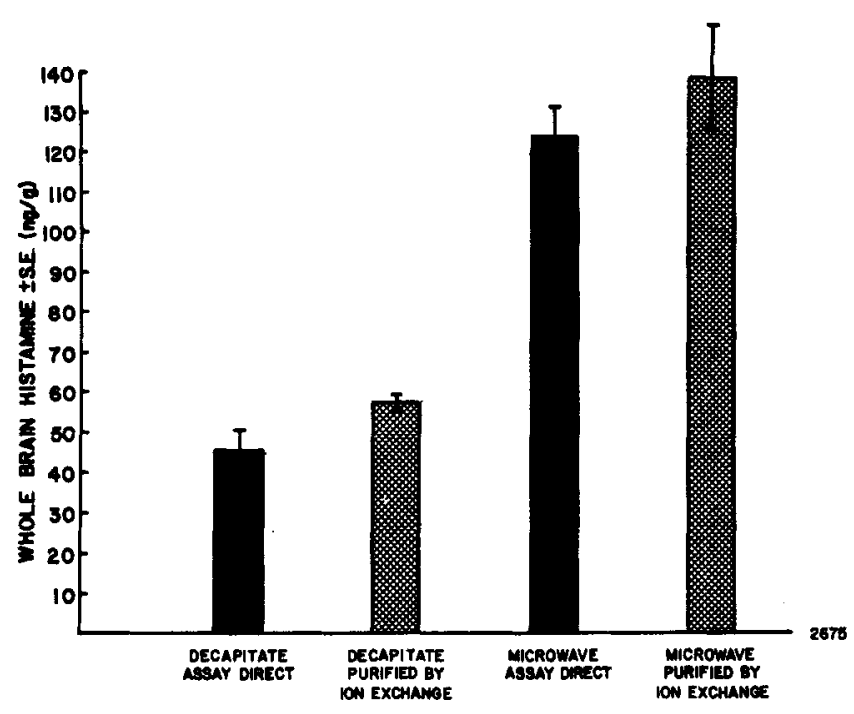

FIG. 2. Rat whole brain histamine after decapitation and focused microwave irradiation with and without cation exchange chromatography. The data are similar to those of Fig. 1 except that the supernatant fractions from the heated brain homogenates were purified by cation exchange chromatography. The histamine content (corrected for recovery) from the purified samples are identical to those assayed directly. Note the elevation after microwave.

In order to attempt to show a rapid post-mortem decline in brain histamine, brains were removed and assayed at various times after decapitation (Fig. 3). A rapid loss of brain histamine was not found. In fact, brain histamine was not changed up to $30 \mathrm{~min}$ after decapitation, but was reduced by $50 \%$ after $60 \mathrm{~min}$. If brain histamine values found after decapitation represent the remainder of a rapidly depleting metabolic pool, then microwave treatment of a rat brain after decapitation (which has low histamine content) should not elevate the histamine content. The histamine content after such treatment was elevated, however (Fig. 4). In fact, histamine levels found after microwave irradiation of an isolated brain were indistinguishable from those of a rat killed by micro- wave heating. Homogenates of brains from decapitated rats did not have higher histamine levels after microwave heating. Rat brain histamine also remained unchanged when animals were immersed in liquid nitrogen for $20 \mathrm{~s}$ prior to decapitation.

If the microwave treatment were causing a redistribution of histamine from pellet to supernatant, the pellet produced by heating and centrifuging brain homogenates from decapitated rats should contain histamine in sufficient quantity to account for the microwave-decapitation discrepancy. Analysis of such pellets by direct assay after extraction revealed $275 \pm 15 \mathrm{ng} / \mathrm{g}$ histamine present (Table 1). This represents over five times the histamine believed to be in the total brain and was therefore suspect. After

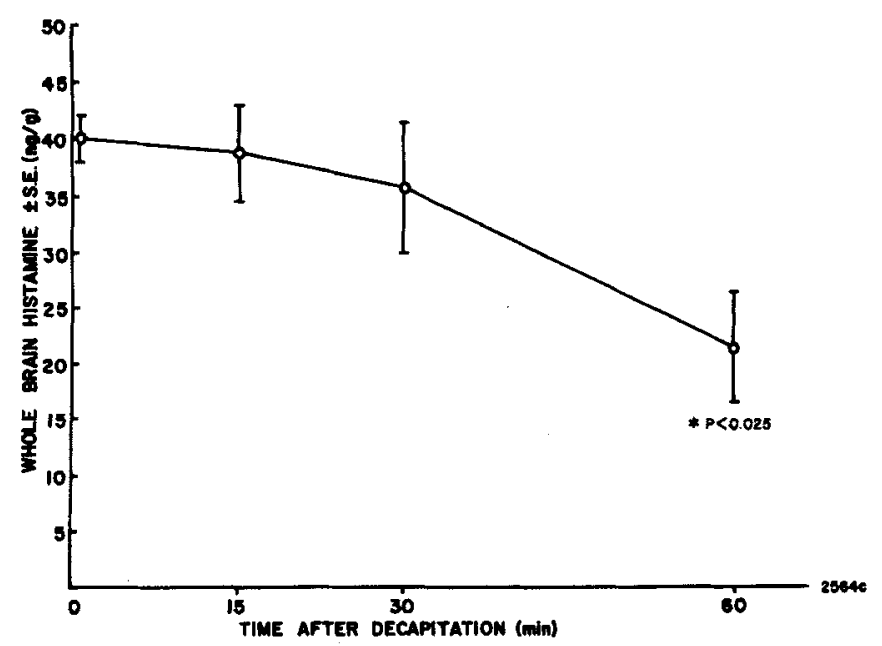

FIG. 3. Time course of rat whole brain histamine after decapitation. The $x$-axis represents the time the head sat at room temperature prior to brain removal and subsequent histamine analysis. At $60 \mathrm{~min}$ a significant decrease in brain histamine was observed. 


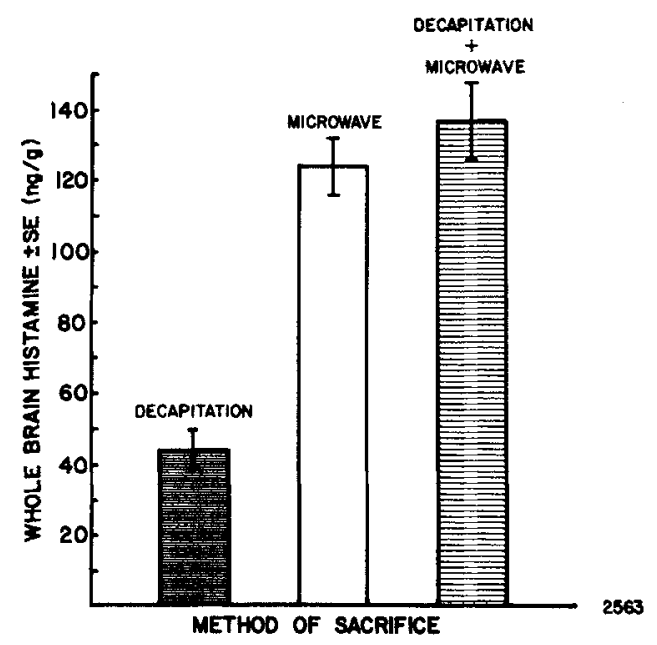

FIG. 4. Rat whole brain histamine after microwave irradiation of isolated brains. Animals were decapitated, their brains removed and assayed directly (column 1) or the isolated brains heated by microwave (column 3). The animals in column 2 were killed by microwave irradiation in vivo. Note that elevated brain histamine levels occur after both microwave procedures.

purification of these pellet extracts, no histamine was found, although histamine added to similar extracts had a recovery of greater than $50 \%$. Calculations based on the maximum sensitivity of the method indicate that pellets had less than $7 \mathrm{ng} / \mathrm{g}$ histamine, whether from decapitated or microwave-treated rats.

If histamine levels were elevated by microwaveinduced histidine decarboxylation, the accumulation of $\left[{ }^{3} \mathrm{H}\right]$ histamine following $\left[{ }^{3} \mathrm{H}\right]$ histidine administration should be enhanced after microwave treatment.
Therefore, $\left[{ }^{3} \mathrm{H}\right]$ histamine and $\left[{ }^{3} \mathrm{H}\right]$ methylhistamine were measured $30 \mathrm{~min}$ after the intraventricular administration of $\left[{ }^{3} \mathrm{H}\right]$ histidine under conditions of decapitation or microwave treatment. The ratio of $\left[{ }^{3} \mathrm{H}\right]$ histamine/total ${ }^{3} \mathrm{H}$ was not significantly different in microwave-treated animals compared to that found after decapitation (Table 2). Labeled methylhistamine accumulation was also unchanged.

\section{DISCUSSION}

Although the radioenzymatic histamine assay has been validated and widely used recently (BEAVEN, 1975; Blumenthal et al., 1974), we have substantiated the identity of the radiochemical product obtained from the assay of brains after microwave treatment. We have also assayed brains with and without partial purification and the results are identical. Furthermore, microwave irradiation does not affect the determination of histamine standards. These findings have convinced us that this method is reliable for brain histamine under these circumstances.

There is little doubt that brain histamine is drastically elevated after microwave treatment. Although rats frequently appeared stressed during restraint, this was not responsible for the microwave effect, since decapitation from the restrainer did not change the values found after decapitation alone (Fig. 1). The brains from microwave treated rats usually weighed slightly less than those from decapitated rats but this is not responsible for a 3 -fold difference. When results are expressed as ng histamine per mg of brain protein, the elevation is still nearly 3-fold (decapitation: $0.38 \mathrm{ng} / \mathrm{mg}$; microwave: $0.98 \mathrm{ng} / \mathrm{mg}$ ).

TABle 1. Histamine CONTENT OF BRAIN PELLETS beFore AND AFTER PURIFICATION

\begin{tabular}{lcc}
\hline \multicolumn{1}{c}{ Method of death } & $\begin{array}{c}\text { Pellet contents } \\
\text { (direct extraction) } \\
\text { mean (ng/g) } \pm \text { S.E. }\end{array}$ & $\begin{array}{c}\text { Pellet contents } \\
\text { (purified) } \\
\text { mean (ng/g) } \pm \text { s.E. }\end{array}$ \\
\hline Decapitation & $275 \pm 15$ & $<7$ \\
Microwave & $305 \pm 18$ & $<7$ \\
\hline
\end{tabular}

Rats were killed by the method indicated and their brains were weighed, homogenized and heated. Pellets obtained by centrifugation were assayed for histamine after organic extraction alone and after subsequent ion exchange chromatography. Each value is the mean of 8 determinations. See Methods section for details.

TABLE 2. EFFECT OF MICROWAVE IRRADIATION ON $\left[{ }^{3} \mathrm{H}\right]$ HISTAMINE AND $\left[{ }^{3} \mathrm{H}\right]$ METHYLHISTAMINE CONTENT AFTER INTRAVENTRICULAR $\left[{ }^{3} \mathrm{H}\right]$ HISTIDINE

\begin{tabular}{lcc}
\hline \multicolumn{1}{c}{ Method of death } & $\begin{array}{c}\text { Ratio of }\left[{ }^{3} \mathrm{H}\right] \text { histamine/ } \\
\text { total }{ }^{3} \mathrm{H}\end{array}$ & $\begin{array}{c}\text { Ratio of }\left[{ }^{3} \mathrm{H}\right] \text { methyl } \\
\text { histamine/total }{ }^{3} \mathrm{H}\end{array}$ \\
\hline $\begin{array}{l}\text { Decapitation } \\
\text { Microwave }\end{array}$ & $0.00291 \pm 0.00039$ & $0.00059 \pm 0.00019$ \\
\hline
\end{tabular}

Rats received intraventricular injections of purified $\left[{ }^{3} \mathrm{H}\right]$ histidine $(20 \mu \mathrm{Ci}$ in $20 \mu \mathrm{l})$. Thirty min later, animals were either decapitated or subjected to microwave irradiation. Brains were removed, homogenized, and assayed for $\left[{ }^{3} \mathrm{H}\right]$ histamine, $\left[{ }^{3} \mathrm{H}\right]$ methylhistamine, and total ${ }^{3} \mathrm{H}$. Results are expressed as ratios of labeled amine to total label and are means of $8 \pm$ S.E. of these ratios. In a typical animal 1,316,159 c.p.m. total ${ }^{3} \mathrm{H}$ is recovered, of which 4230 c.p.m. are histamine and 858 c.p.m. are methylhistamine. 
If a rapid metabolic loss of histamine were occurring after decapitation, then microwave treatment in vivo might be expected to prevent such a loss. This could provide for a more accurate measurement of histamine. However, microwave treatment of a brain after decapitation (at a time when the presumed loss has alraedy occurred) should not elevate the histamine content. Our results clearly demonstrate that such elevation does occur (Fig. 4). This experiment is necessary in any system where microwave-induced inactivation of enzymes is hypothesized as the mechanism of the microwave effect. Whereas the measurement of enzyme activity after various microwave treatments provides a correlation (albeit an important one), the conclusion from the present experiment can be definitive. In this case we believe that it is: the elevation in brain histamine after microwave irradiation is not due to an inactivation of rapid catabolic processes.

Our other evidence is also consistent with this conclusion. No rapid loss of brain histamine was found after decapitation (Fig. 3). When brain protein is denatured by homogenizing in acid, the histamine content after decapitation is the same as in samples homogenized and heated in buffer. This would not be expected if rapid metabolic changes were occurring, since the acid treatment inactivates protein 20-30 s faster than does heating the samples in buffer. We have also measured rat brain histamine in animals killed by immersion in liquid nitrogen, a procedure sometimes used to minimize postmortem enzymatic changes (APRISON et al., 1974). This treatment had no effect on brain histamine compared to decapitation.

It would appear that the microwave effect does require a morphologically intact brain, since microwave treatment of brain homogenates from decapitated rats did not elevate the histamine content. Further interpretation of this observation seems difficult, although this inability to demonstrate histamine elevation in vitro argues against a microwave-induced conversion of other substances to histamine. It should be pointed out, however, that in the present experiments the brain homogenates were at $4^{\circ} \mathrm{C}$ prior to microwa ve treatment. RiCHARDSON \& SCUDDER (1976) have shown that the ability of microwave irradiation to alter brain GABA levels is a function of the initial brain temperature. These observations may be relevant to our results with microwave treated homogenates although this treatment clearly heated the sample and denatured the protein present.

The histamine content found after analysis of the unpurified brain pellet was shown to be artifactual by subsequent purification. The artifact is not found after organic extraction of supernatant fractions, since reasonable whole brain histamine values have been obtained this way. Homogenates extracted in this manner prior to heating or centrifugation were also found to be spuriously elevated. The identity of this heat stable, lipid soluble artifact is not known. Assuming that most of the histamine in the pellet is freed by extraction, it seems clear that little or no histamine is actually in the pellet. Theoretically, extraction-resistant histamine could be in the pellet and be freed by microwave treatment. Unless histamine were bound covalently, however, the solvent should have removed it. We have also sonicated these pellet homogenates prior to extraction, with no difference in the results obtained.

It seemed important to find out if microwave treatment could decarboxylate histidine in vivo, since many amine artifacts could be produced and measured this way. A conversion of $1-2 \%$ of brain histidine to histamine could explain the observed changes in histamine content, since histidine levels are so much higher (ENWONwU \& WoRTHINGTON, 1975). Thirty minutes after the $20 \mu \mathrm{Ci}$ injection of $\left[{ }^{3} \mathrm{H}\right]$ histidine, $6-7 \%$ of the label remains in brain, of which $85-90 \%$ remains as histidine. Thus, a decarboxylation of $1 \%$ of this histidine would have enhanced the labeled histamine found from about 3000 to 15,000 c.p.m., and the $\left[{ }^{3} \mathrm{H}\right]$ histamine $/{ }^{3} \mathrm{H}$-total ratio would have been proportionately elevated.

Since no difference was found between the ratios from decapitated and microwave treated rats, it can be concluded that microwave-induced histidine decarboxylation does not occur. This conclusion requires the assumption that the labeled amino acid reached all endogenous compartments associated with histamine synthesis. The work of DISMUKES \& SNYDER (1974) supports this assumption by demonstrating a similar turnover rate of brain histamine measured by isotopic and non-isotopic techniques. The isotopic technique used by these investigators is identical to the one used presently. The $30 \mathrm{~min}$ time point was chosen because this is near the time of maximum labeled histamine present (PoLlard et al., 1974). This labeled histamine found after $30 \mathrm{~min}$ further substantiates the rapid kinetics of brain histamine found by others (Pollard et al., 1974; Dismukes \& SNYDER, 1974). In addition, the lack of microwave effect further argues against an inactivation of rapid metabolic processes since labeled histamine was measured at a time when both decarboxylation and methylation were occurring (Pollard et al., 1974).

We have shown that rat brain histamine content is elevated after focused microwave irradiation. This elevation is not due to an artifact in measuring histamine, is not due to an inactivation of rapid metabolic processes, is not attributable to histamine redistribution, is not due to histidine decarboxylation, but is dependent upon intact brain morphology. Microwave-induced formation of histamine from other substances seems unlikely but remains the only plausible explanation. Metabolic formation of histamine from substances other than histidine is not known. We have also shown that histamine measurements using the radioenzymatic assay are unreliable if extractions are made from non-denatured homogenates without subsequent purification.

Elevations per se in neurotransmitter content fol- 
lowing microwave treatment should not be construed as evidence for a more accurate measurement of that substance. Neither should it be construed as evidence for a system with a rapid turnover, as others have suggested (MERRITT et al., 1975). Systems with rapid rates of turnover do not necessarily demonstrate rapid post-mortem changes. Only when synthesis and degradation become unbalanced do rapid changes in content occur, as is apparently the case for post-mortem acetylcholine (STAvinoHa et al., 1973). Our results demonstrate that this is not the case for histamine.

Note added in proof: Recently two groups of investigators have reported that brain tissue forms peptido-histamines [REICHELT et al. (1976) J. Neurochem. 26, 811-815 and Konishi \& Kakimoto (1976) J. Neurochem. 27, 1461-1463]. One should examine the possibility that microwave treatment could be forming histamine from such substances endogenously.

\section{REFERENCES}

Aprison M. H., SheA P. A. \& Richter J. A. (1974) in Choline and Acetylcholine: Handbook of Chemical Assay Methods (Hanin I., ed.) pp. 63-80. Raven Press, New York.

deBalbian-Verster F., Robinson C. A., Hengeveld C. A. \& Bush E. S. (1971) Life Sci. 10, 1395-1402.

BEAVEN M. A. (1975) in Handbook of Psychopharmacology (IVERSEN L. L., IVERSEN S. D. \& SNYDeR S. H., eds.) Vol. 1, pp. 266-295. Plenum Press, New York.

BeAven M. A. \& JaCOBSEN S. (1971) J. Pharmac. exp. Ther. 176. $52-64$.
Beaven M. A., Jacobsen S. \& Horakova Z. (1971) Clin. Chim. Acta 37. 91-103.

Blumenthal M. N., Roitman B., Carlson G. \& Fish L. (1974) Biochem. Med. 11, 312-317.

DisMUKes K. \& SNyder S. H. (1974) Brain Res. 78, 467-481.

DisMuKes K. \& SNYDER S. H. (1974) Brain Res. 78, 467-481.

Enwonwu C. O. \& Worthington B. S. (1975) J. Neurochem. 24, 941-945.

Guidotti. A., Cheney D. L., Trabucchi M., Doteuchi M. \& WANG C. (1974) Neuropharmacology 13. 1115-1122.

Hough L. B. \& Domino E. F. (1975) Pharmacologist 17. 179.

Lowry O. H., Rosebrough N. J., Fark A. L. \& Randall R. J. (1951) J. biol. Chem. 193, 265-275.

Merritt J. H., Medina M. A. \& Frazer J. W. (1975) Res. Commun. Chem. Path. Pharmac. 10, 751-754.

Pollard H., Bischoff S. \& Schwartz J. C. (1974) J. Pharmac. exp. Ther. 190, 88-99.

Richardson D. L. \& Scudder C. L. (1976) Life Sci. 18. $1431-1440$.

SChWARTZ J. C. (1975) Life Sci. 17, 503-518.

SNyder S. H., Axelrod J. \& Bauer H. (1964) J. Pharmac. exp. Ther. 144, 373-379.

Stavinoha W. B., Weintraub S. T. \& Modak A. T. (1973) J. Neurochem. 20, 361-371.

TAYLOR K. M. (1975) in Handbook of Psychopharmacology (IVERSEN L. L., IVERSEN S. D. \& SNYdeR S. H., eds.) Vol. 3, pp. 327-379. Plenum Press, New York.

TAYLOR K. M. \& SNYdeR S. H. (1971) J. Pharmac. exp. Ther. 173. 619-633.

Weintraub S. T., Stavinoha W. B., Pike R. L., Morgan W. W., Modak A. T, Koslow S. H. \& Blank L. (1975) Life Sci. 17, 1423-1428. 